\title{
RENAL FAILURE AFTER SURGERY FOR PRIMARY HYPERPARATHYROIDISM: IS ACUTE REDUCTION OF PARATHYROID FUNCTION A RISK FACTOR?
}

\author{
doi: $10.1590 / \mathrm{S} 1807-59322009000400017$
}

Fabio Luiz de Menezes Montenegro, Regina Matsunaga Martin, Pedro Henrique Silveira Corrêa

\section{INTRODUCTION}

A possible deleterious effect of parathyroidectomy on renal allograft function has been discussed in recent literature. ${ }^{1}$ Schwarz et al. observed a correlation between acute kidney dysfunction and the degree of parathyroid hormone (PTH) reduction following a parathyroidectomy for tertiary hyperparathyroidism (HPT). ${ }^{2}$ This effect seems to be in contrast to some physiological studies demonstrating that injection of PTH is associated with a reduction in the glomerular capillary ultrafiltration coefficient $(\mathrm{Kf}) .^{3}$ Based on this evidence, the acute reduction in PTH would theoretically improve glomerular filtration.

In general, the reversal of HPT would prevent further renal damage. Stable or improved renal function are the observed clinical courses for most patients in the longrun, but we observed a different pattern during the first 48 hours after the operation, with a transitory increase in creatinine levels above $10 \%$ in 77 of 105 patients after parathyroidectomy for primary HPT. ${ }^{4}$ Creatinine levels increased more than $50 \%$ in 18 patients $(17.1 \%) .{ }^{4}$ In renal stone patients, a slight increase in creatinine after successful resection of a parathyroid adenoma was recently commented 5 .

The elevation of creatinine was transient and clinically silent in most of our patients. However, acute deterioration of renal function requiring dialysis occurred in two of 183 (1.1\%) patients with primary HPT who underwent surgery from 1997 to 2007. The outcome of these cases may indicate a potentially relevant role of the parathyroid glands in renal regulation.

Sections of Head and Neck Surgery and Endocrinology, Department of Internal Medicine, Faculdade de Medicina da Universidade de São Paulo, São Paulo/SP, Brazil.

Email: fabiomonte@uol.com.br

Tel.: 55113069.6425

\section{CASE REPORTS}

The first patient was a 61-year-old female who was admitted in June 2001. Her past medical history included a right nephrectomy due to presumed nephrolitiasis at the age of 18 , without any new episodes since that time. From 1989 to 2000 , her creatinine varied from 0.9 to $1.1 \mathrm{mg} / \mathrm{dL}$ (normal range 0.6 to $1.4 \mathrm{mg} / \mathrm{dL}$ ). In April, 1997, her levels of total calcium, phosphorus, and creatinine were $10.4 \mathrm{mg} /$ $\mathrm{dL}$ (normal 8.5 to $10.5 \mathrm{mg} / \mathrm{dL}$ ), $2.0 \mathrm{mg} / \mathrm{dL}$ (normal 2.3 to 4.6 $\mathrm{mg} / \mathrm{dL}$ ), and $0.9 \mathrm{mg} / \mathrm{dL}$, respectively.

Although her HPT was rather stable from 1997 to 2000, marked hypercalcemia developed during the final six months. She was then referred to our hospital. Upon admission, she was oriented, hydrated, without edema, had an arterial blood pressure equal to 120 x $90 \mathrm{mmHg}$, weighed $48.1 \mathrm{~kg}$, and was 1.5 meters in height. Laboratory test values were: total calcium $=17.8 \mathrm{mg} / \mathrm{dL}(8.5-10.5$ $\mathrm{mg} / \mathrm{dL})$, phosphorus $=6.4 \mathrm{mg} / \mathrm{dL}(2.3-4.6 \mathrm{mg} / \mathrm{dL})$, urea $=$ $66 \mathrm{mg} / \mathrm{dL}(10-45 \mathrm{mg} / \mathrm{dL})$, creatinine $=2.9 \mathrm{mg} / \mathrm{dL}$, and PTH $=3,262 \mathrm{pg} / \mathrm{mL}(11-62 \mathrm{pg} / \mathrm{mL})$. Urinary ultrasonography was compatible with a previous right nephrectomy. The left kidney measured 12.1 x 5.9 x $5.1 \mathrm{~cm}$. Cortico-medular thickness was normal, but exhibited increased echogenicity. No stones or hydronephrosis were present. The patient began saline hydration $(4,000 \mathrm{~mL} /$ day $)$ and intermittent furosemide, maintaining a daily urinary flow close to 6,000 $\mathrm{mL}$. Her calcium, urea, and creatinine levels dropped to 15.7 $\mathrm{mg} / \mathrm{dL}, 35 \mathrm{mg} / \mathrm{dL}$, and $2.1 \mathrm{mg} / \mathrm{dL}$, respectively. In a 24-hour urine sample of $5,850 \mathrm{~mL}$, urinary calcium was $748 \mathrm{mg}$. Preoperative imaging with technetium sestambi revealed a mediastinal parathyroid. Bone mineral density presented a $\mathrm{T}$ score of -4.1 for the lumbar spine and -3.4 for the femoral neck.

The day before the operation, the patient's hemoglobin was $8.8 \mathrm{mg} / \mathrm{dL}$, and red blood cells were transfused without any complication. On the morning before the operation, her creatinine was $2.1 \mathrm{mg} / \mathrm{dL}$, urea was $20 \mathrm{mg} / \mathrm{dL}$, phosphorus 
was $4.0 \mathrm{mg} / \mathrm{dL}$, and ionized calcium was $8.6 \mathrm{mg} / \mathrm{dL}$. An ectopic parathyroid adenoma of the left inferior parathyroid (40 × $20 \times 10 \mathrm{~mm})$ was excised using a cervical approach. Biopsy of the left superior parathyroid was normal, without any evidence of hyperplasia. The operation was uneventful. A single dose of one gram of cefazolin was administered as an antibiotic prophylaxis. No haemodynamic instability was observed, and no other potential nephrotoxic agents were employed before or during the operation. The patient received $3,000 \mathrm{~mL}$ of crystaloid during the operation. Immediately after the operation, the patient was oliguric ( $270 \mathrm{~mL} / 24$ hours) despite the use of furosemide. On the first postoperative day, her PTH was undetectable, creatinine was $3.0 \mathrm{mg} / \mathrm{dL}$, and urea was $37 \mathrm{mg} / \mathrm{dL}$. An ultrasound did not reveal any evidence of urinary obstruction. On the second postoperative day, she continued to be oliguric, her weight increased $10 \%$, and her creatinine concentration was 4.1 $\mathrm{mg} / \mathrm{dL}$. Hemodialysis was necessary due to hypervolemia. Although partial diuresis had returned (24 hours diuresis of $1,250 \mathrm{~mL}$ on the fifth postoperative day, $1,550 \mathrm{~mL}$ on the seventh, and $1,150 \mathrm{~mL}$ on the eighth), dialysis was still necessary before and after discharge. On the seventh postoperative day, laboratory values were: $\mathrm{PTH}=93 \mathrm{pg}$ / $\mathrm{mL}$, urea $=97 \mathrm{mg} / \mathrm{dL}$, creatinine $=5.4 \mathrm{mg} / \mathrm{dL}$, phosphorus $=$ $1.9 \mathrm{mg} / \mathrm{dL}$, total calcium $=6.5 \mathrm{mg} / \mathrm{dL}$, and ionized calcium $=4.5 \mathrm{mg} / \mathrm{dL}$. Postoperative calcium and phosphorus were indicative of severe hungry bone syndrome. On the $22^{\text {nd }}$ postoperative day, she was allowed to leave the hospital for an office follow-up in her city of residence. After 6 years, she is still alive and undergoing regular dialysis. Figure 1 shows the patient's estimated glomerular filtration rate, which was calculated at http://ukidney.com/egfr-calculator.html.

The second patient was a 37 -year-old male. His first appointment at the institution was a consultation in rheumatology. His history began ten years before admission

Estimated Glomerular Filtration Rate (eGFR) Case 1

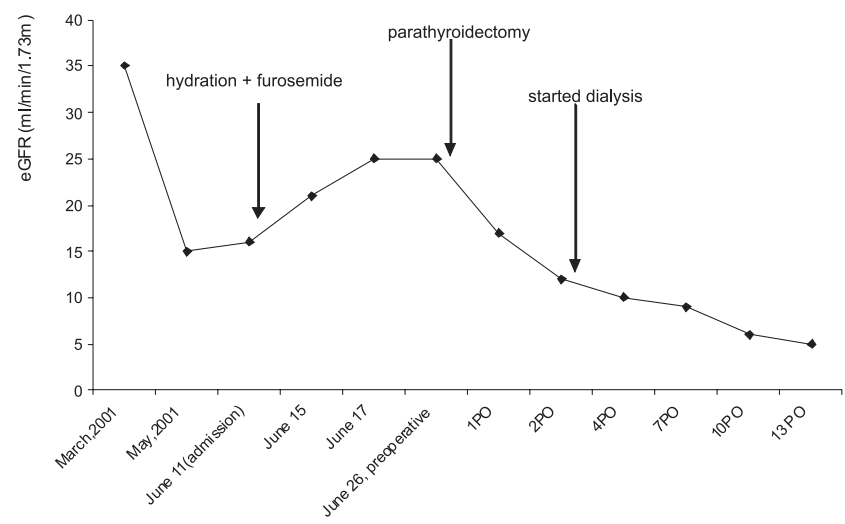

Figure 1 - Estimated glomerular filtration rate before and after parathyroidectomy of the first patient with recurrent episodes of kidney stones without further investigation. After five years, the patient was misdiagnosed with rheumatic disease (foot pain), and piroxicam was initiated. Three years prior to this study, hypertension ensued and propranolol administration was added. He reported that one physician had observed a "renal" problem. Unfortunately, the laboratory tests performed during this period were unavailable in his chart. Eight months before admission, he fell from a bicycle and suffered proximal fractures of both the right femur and humerus. At his first consultation at the institution, he was in very poor condition, was dehydrated, and was unable to walk. He was immediately referred to the emergency department. He looked pale and dehydrated, with blood pressure $=110$ x $70 \mathrm{mmHg}$, heart rate $=120$ beats per minute, and weight $=47 \mathrm{~kg}$, and height $=1.6$ meters. Laboratory test results were: hemoglobin $=8.9 \mathrm{~g} / \mathrm{dL}$, total calcium $=12.2 \mathrm{mg} / \mathrm{dL}$, phosphorus $=9.8 \mathrm{mg} / \mathrm{dL}$, creatinine $=3.94 \mathrm{mg} / \mathrm{dL}$, urea $=$ $330 \mathrm{mg} / \mathrm{dL}$, and PTH $=6,556 \mathrm{pg} / \mathrm{mL}$. Urinary ultrasound provided a measurement for the right kidney of $11.1 \mathrm{x}$ $5.1 \times 6.7 \mathrm{~cm}$ (cortical thickness $1.7 \mathrm{~cm}$ ), and for the left kidney 11.8 x 4.0 x $5.0 \mathrm{~cm}$ (cortical thickness $1.6 \mathrm{~cm}$ ). An increased echogenicity in the renal cortex as well as in the renal pyramids were noted, suggesting nephocalcinosis. A one-centimeter stone was observed in the urinary bladder, without signs of hydronephrosis. Saline hydration was initiated, and red blood cells were transfused. The patient presented a good response to hydration, with daily diuresis ranging from $2,550 \mathrm{~mL}$ to $5,150 \mathrm{~mL}$. Bone mineral density presented a $\mathrm{T}$ score of -2.58 for the lumbar spine and -3.6 for the femoral neck. Four days after admission, a spontaneous fracture occurred in the shaft of the right humerus. The day before the operation, diuresis was $3,150 \mathrm{~mL}$, creatinine = $1.81 \mathrm{mg} / \mathrm{dL}$, and urea $=66 \mathrm{mg} / \mathrm{dL}$. On the morning of the operation, creatinine $=1.60 \mathrm{mg} / \mathrm{dL}$ and urea $=59 \mathrm{mg} / \mathrm{dL}$. The patient underwent cervical exploration and a parathyroid adenoma of 40 × 27 x $25 \mathrm{~mm}$ was excised. Immediately after the operation, he was anuric, even after volume expansion. His total calcium and phosphorus dropped to $7.1 \mathrm{mg} /$ $\mathrm{dL}$, and $3.6 \mathrm{mg} / \mathrm{dL}$, respectively. He was oliguric on the first postoperative day $(330 \mathrm{~mL} / 24 \mathrm{~h})$, and he underwent hemodialysis on the second postoperative day. He underwent another six sessions, and renal function partially returned (from $530 \mathrm{~mL}$ on the third postoperative day to $1,560 \mathrm{~mL}$ on the seventh). No further dialysis was required, despite the occurrence of staphylococcic endocarditis requiring vancomycin for four weeks, and an orthopedic operation for the humeral fracture, which is in contrast to the responses observed immediately after the parathyroidectomy. After a four-month hospital stay, the patient was discharged for office follow-up. Unfortunately, he died six months after the 


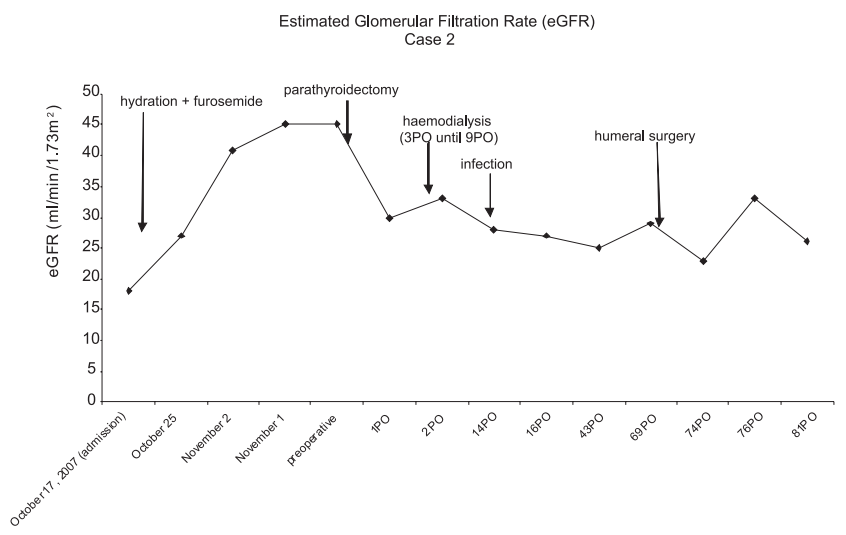

Figure 2 - Estimated glomerular filtration rate before and after parathyroidectomy of the second patient

operation, apparently from complications associated with infection. Figure 2 depicts the estimated glomerular filtration rate during his admission, calculated as described above.

\section{DISCUSSION}

Primary hyperparathyroidism is less frequently detected in the developing world, but more severe presentations associated with both renal and skeletal compromise are not uncommon in developing countries ${ }^{6}$. Severe hypercalcemia is a well recognized cause of renal damage. Its resolution after parathyroidectomy is associated with improved renal function. However, some patients display worsened kidney function after parathyroidectomy. ${ }^{6}$

During the preoperative period, a consistent response to hydration and forced diuresis apparently prevented further renal compromise in both patients. The postoperative course of case one was unexpected at that time. Besides pre-existing renal failure, additional common risk factors such as diabetes, hypotension, drug nephrotoxicity, or calculus obstruction were not evident. ${ }^{7}$ In fact, some cases of decreased kidney function after parathyroidectomy can be found in the literature. ${ }^{8,9}$

The mechanism of this decrease in renal function after parathyroidectomy remains unclear. Basic studies have been performed to assess the physiological action of PTH on renal function, with contrasting results. In rats, Schor et al. suggested that PTH exerts a mild vasoconstrictive effect on the renal cortical microcirculation, and this effect is dependent on the activity of angiotensin II. ${ }^{10}$ However, another study suggested that PTH is a potent renal vasodilator peptide. ${ }^{11}$ These apparently opposite results raise the question as to whether PTH is only a marker of other hormones released from the parathyroid gland, as conjectured in a recent study that observed a correlation between PTH levels and incident hypertension. ${ }^{12}$ Another hypothesis is acute interruption of PTH effects and transient persistence the effects of an antagonist or another substance with opposite activity. ${ }^{13}$

The postoperative course for the patients presently described was in great accordance with the clinical observations of Edvall at the Karolinska Institute. ${ }^{14} \mathrm{He}$ described two different effects of the overactivity of the parathyroid glands on the kidney: functional changes (diminished reabsorption, a marked increase in the glomerular filtration rate, and a less marked increase in renal plasma flow) and an organic tubular lesion (evidenced by interference in the maximal rate of tubular transport of para-aminohippurate). Functional changes rapidly subside after removal of the overactive parathyroid tissue. Edvall stated that lowered reabsorption capacity was present in all cases, but that increased glomerular filtration rates and renal plasma flow were noted only in cases that clearly displayed renal damage preoperatively. The organic tubular lesion was probably irreversible. He proposed that a parathyroidectomy could represent a risk factor for a "fatal" loss of "compensatory" kidney function in some patients with advanced renal damage due to HPT. $\cdot{ }^{14} \mathrm{He}$ emphasized the importance of early HPT diagnosis in order to stop the irreversible tubular destruction..$^{14}$ Laroche et al. ${ }^{15}$ observed two cases of end-stage renal failure after parathyroidectomy, although they did not mention Edvall's work. Edvall's observation is also a reasonable explanation for the clinical enigma associated with the decreased function of the transplanted kidney after parathyroidectomy. ${ }^{16}$

If parathyroidectomy may represent a risk factor for acute-on-chronic kidney injury in patients with advanced HPT, perhaps a better understanding of the underlying mechanism would provide preventive strategies, as currently studied in contrast-induced acute kidney injury. ${ }^{17}$ Besides the importance of avoiding anti-inflammatory drugs and radiological contrast agents immediately after parathyroid resection, present cases illustrate that the study of the physiological effects of the parathyroid glands and related substances (such as parathyroid hormone-related protein) ${ }^{18}$ on the kidney are of clinical interest. Further, they reinforce the contribution of clinical medicine to our understanding of renal physiology. ${ }^{19}$ 


\section{REFERENCES}

1. Triponez F, Clark OH, Vanrenthergem Y, Evenepoel P. Surgical treatment of persistent hyperparathyroidism after renal transplantation. Ann Surg. $2008 ; 248: 18-30$.

2. Schwarz A, Rustien G, Merkel S, Radermacher J, Haller H. Decreased renal transplant function after parathyroidectomy. Nephrol Dial Transplant. 2007;22:584-91.

3. Humes HD, Ichikawa I, Troy JL, Brenner BM. Evidence for a parathyroid hormone-dependent influence of calcium on the glomerular ultrafiltration coefficient. J Clin Invest. 1978;61:32-40.

4. Montenegro FLM, Ferreira GF, Lourenço Jr DM, Martin RM, Arap SS, Correa PH, et al. Transitory decrease of renal function after parathyroidectomy: a clinical observation indicating the renal hemodynamic effect of parathyroid hormone? Rev Bras Cir Cabeça Pescoço. 2007;36:196-201.

5. Evan AE, Lingerman JE, Coe FL, Miller NL, Bledsoe SB, Sommer AJ, et al. Histopathology and surgical anatomy of patients with primary hyperparathyroidism and calcium phosphate stones. Kidney Int. 2008;74:223-9.

6. Pradeep PV, Mishra A, Agarwal G, Agarwal A, Verma AK, Mishra SK. Long-term outcome after parathyroidectomy in patients with advanced primary hyperparathyroidism and associated vitamin D deficiency. World J Surg. 2008; 32:829-35.

7. Sear JW. Kidney dysfunction in the postoperative period. Br J Anaesth. 2005;95:20-32.

8. Tornblom N. Renal crises following the extirpation of parathyroid adenomata. Acta Endocrinol. 1949; 2:178-97.

9. Collier VU, Mitch WE. Accelerated progression of chronic renal insufficiency after parathyroidectomy. JAMA. 1980; 244:1215-8.
10. Schor N, Ichikawa I, Brenner BM. Mechanisms of action of various hormones and vasoactive substances on glomerular ultrafiltration in the rat. Kidney Int. 1981;20:442-51.

11. Zaladek-Gil F, Costa-Silva VL, Malnic G. Effects of parathyroid hormone on urinary acidification in the rat. Braz J Med Biol Res. 1991;24:1063-6.

12. Taylor EN, Curhan GC, Forman JP. Parathyroid hormone and the risk of incident hypertension. J Hypertens. 2008;26:1390-4.

13. Massfelder T, Parekh N, Endlich K, Saussine C, Steinhausen M, Helwig JJ. Effect of intrarenally infused parathyroid hormone-related protein on renal blood flow and glomerular filtration rate in the anaesthetized rat. Br J Pharmacol. 1996;118:1995-2000.

14. Edvall CA. Renal function in hyperparathyroidism: a clinical study of 30 cases with special reference to selective renal clearance and renal vein catheterization. Acta Chirur Scand Supll. 1958;114(Suppl 229):1-56.

15. Laroche M, Garrette F, Rostaing L, Catagrel A, Mazières B. Endstage renal failure following parathyroidectomy for advanced primary hyperparathyroidism. Rev Med Interne. 1998;19:787-91.

16. Schlosser K, Endres N, Celik I, Fendrich V, Rothmund M, Fernández ED. Surgical treatment of tertiary hyperparathyroidism: the choice of procedure matters! World J Surg. 2007;31:1947-53.

17. McCullough PA. Multimodality prevention of contrast-induced kidney injury. Am J Kidney Dis. 2008;51:169-72.

18. Esbrit P, Santos S, Ortega A, Fernandez-Agulo T, Velz E, Troya S, et al. Parathyroid hormone-related protein as a renal regulating factor. Am J Nephrol. 2001;21:179-84.

19. Epstein FH. Contributions of clinical medicine to renal physiology. Kidney Int. 1996;49:1534:8. 